\title{
A New Face at the Door...
}

\author{
Arthur M. Michalek ${ }^{1}$
}

Published online: 12 January 2016

(C) American Association for Cancer Education 2016

Happy New Year and a fond adieu to the old. It has been another remarkable year. A year filled with jeers and cheers. A year of accomplishments and renewed commitments. This was most evident at our recent annual meeting in Tucson, Arizona. The International Cancer Education Conference, a.k.a. the annual AACE/CPEN meeting, was true to its billing as an international conference. Kudos goes to the co-chairs of the meeting Sheryl Ness (Mayo Clinic) and Amr Soliman (University of Nebraska), and all the members of their Committee as well as to Maria Bishop who along with her team did such a marvelous job with local arrangements. The setting and substance for this year's meeting was truly inspirational. This year's conference theme was Cancer Education in Diverse Populations: Disparities, Genomics and Innovations. As the co-chairs explained, the theme was "chosen to highlight the global perspective of educational issues across the continuum of the cancer experience for patients and their families with a focus on serving the needs of special populations and addressing disparities in cancer care. From prevention through treatment, to survivorship or end-of-life care, cancer educators and researchers are at the forefront of this evolving practice promoting excellence in cancer patient education, services, and cancer care." The quality of the presentations at the meetings gets better and better. There were far too many superb presentations to mention in this editorial. The schedule, per usual, was packed from early Wednesday mornings preconference workshops to the closing ceremony of late Friday afternoon. This year's Harvey lecture was given by Diane Zipursky Quale who along with her late husband, John, launched the

Arthur M. Michalek

amm3@buffalo.edu

1 University at Buffalo, Buffalo, NY, USA
Bladder Cancer Advocacy Network-BCAN (www.bcan. org). BCAN's mission is to advance research, provide information and support, and raise awareness on bladder cancer. Her presentation left no doubts as to the breath and success of their organization. She recounted its remarkable growth from its nascent beginning as a private conversation between husband and wife to today's incredibly successful and supportive organization. I encourage all to visit their website to see how you can become a bladder cancer advocate.

Thanks go to outgoing President Gilad Amiel for inviting her. The opening plenary sessions were given by Dr. David Alberts (Can Diet and Physical Activity Prevent Cancer Progression) followed by Dr. Charles Kelly (The Genomic Revolution, Patient Education and Shared Decision Making). Other plenary sessions were proffered by Drs. Harris and Loescher (Skin Cancer Prevention Education), Dr. Judith Kaur (Cancer Education with American Indian and Alaska Native Populations), and Drs. Korczak and Lei (NCI R25 cancer Education Program). One of the highlights of the annual meeting is the awarding of the Dr. Margaret Hay Edwards award. This year's recipient was Dr. C. Michael Brooks (and his lovely bride Diane) who is the past president of the AACE (1994) and an internationally renowned cancer educator. Michael has been a fixture at our meetings for many years and has mentored countless educators throughout his career. In addition to these sessions, there were many concurrent sessions in which valuable and innovative information was presented.

As in all past meetings, opportunities for rekindling old acquaintances and extending professional networks abounded. The setting for this year's meeting, the Loews Ventana Canyon Resort, was a perfect place for relaxation and interaction. I saw many a private confab taking place at the pool, the spa, and along the lovely desert walking trail. 
Highlights included a stargazing experience and dinner at the botanical garden (who would have thought that a nonalcoholic sage punch could taste so good). As you start planning activities for the New Year, please make a point of reserving 14-17 September 2016 when we will be holding our next annual meeting in Bethesda, Maryland, at the Hyatt Regency Bethesda. Please visit www.attendiced.org for details as they develop. Make a New Year's resolution to bring some new members into the association and to the meeting.

At the annual meeting, we also witnessed the passing of the leadership gavel from Gilad Amiel to Amr Soliman. Gilad did a remarkable job despite being separated from us by thousands of miles having relocated from Baylor and to the Ramban Health Care Campus in Haifa, Israel, where he is Director of Urology. I suspect that in addition to his continuation in our association, he will become even more active in the European Association for Cancer Education. Amr Soliman, as many of you know, is a world-renowned authority in cancer epidemiology/cancer education and has led numerous projects in northern Africa. To that end, he is leading a team to increase our membership in Africa. He and others within the association recently attended the AORTIC meeting in Morocco. The outcome from that meeting has been quite encouraging. Kathleen Heneghan reports that the AACE was well received. Attendance at the presession was about 75 people. Early reports are that 45 to 60 individuals completed forms for membership. Copies of the JCE were readily snatched up and gone by lunch of the first day. Thanks to Amr; the Director of the UICC was the moderator for our session and expressed interest in developing a collaboration between the UICC and the AACE. So, it looks as if the association will experience significant growth in the international market in the year 2016 and beyond. I will be reporting more on these activities in forthcoming issues.

The annual meeting is also when we hold the annual editorial board meeting of the JCE. We welcomed new editorial board members to the meeting as well as Melissa James who is our new Publishing Editor at Springer. At the meeting, I was pleased to report a bevy of positive metrics. The impact factor of the JCE is now at 1.23 where only two short years ago, it was 0.88 . A journal's impact factor is the average number of citations received per paper published in that journal. A rising impact factor is a reflection of the increasing quality of articles published and to the diligence of our reviewers. The JCE now ranks among the top 20 (15th place) of medical education journals. We continue to see an increase in the number of articles submitted to the journal as well as those from nonNorth American countries. We hope that this trend in quality and geographic diversity will continue in the years ahead. In the first issue of last year's Journal I reported that the number of downloads via Springer link has grown over the past three years from 19,000 to nearly 42,000 downloads. This past year, we experienced nearly 46,000 downloads. Since 2012, submissions to the Journal have more than doubled in a rejection right has tripled. While the JCE is becoming more selective, we remain true to our roots in nurturing trainees and first time authors and assisting them in the publication of their first works. In this issue of the Journal, you will also find a roster of reviewers who contributed their time and knowledge to the evaluation of manuscripts received this past year. Thank you to all the authors and reviewers, of these wonderful manuscripts.

In this issue, you will find a book review proffered by Dr. Melany Cueva. The book of interest is co-edited by one of our members (Carolyn Messner) and entitled "Handbook of Oncology Social Work: Psychosocial Care for People with Cancer". Melany uses terms like "a must read for all oncology practitioners", "comprehensive", "extensive", "comprehensive overview". Dr. Cueva's review is also a must read!

Let me close by wishing you all a healthy, productive New Year and offer for your reflection the last stanza of "The Death of the Old Year" by Lord Alfred Tennyson.

His face is growing sharp and thin.

Alack! our friend is gone,

Close up his eyes: tie up his chin:

Step from the corpse, and let him in

That standeth there alone,

And waiteth at the door.

There's a new foot on the floor, my friend,

And a new face at the door, my friend,

A new face at the door.

Be well. 
And the Winner is...Awards from the 2015 I.E. Meeting:

- Best Poster:

- First place, Research: Kristen Wells, "Pilot Testing of a Spanish Language Biobanking Educational Intervention: Biobanco: una esperanza de cura para el cáncer"

- Second place (tie), Research: Christy Widman, "Building a Foundation to Accelerate Rates of HPV Vaccination in Western New York"

- Second place (tie), Research: Kathleen Heneghan, "Ostomy Home Skills Kit (OSHK) is Effective at Preparing Patients to Confidently Manage Their Post-Operative Recovery"

- First place, Innovations: Donna Branson, “A Cost Effective Approach: Using Social Media to Promote a Cancer Prevention Video"

- Second place, Innovations: Lorene Payne, "International Patient Orientation Video Series"

\section{- Best Abstract:}

- Paul McCann, Veronica Bryksa, Diane Marley: "Patients and Families for change-lessons learned from the implementation of RENEW, a post treatment education initiative"
- Jennifer Wang, Chasity Walters: "Using Virtual Programs to Deliver Education and Support to People with Cancer and their Caregivers"

- Aman Sium, Janet Papadakos, Angela Dosis, Vincenzo Addario, Audrey Jusko Friedman, Danny Ghazarian: "Making pathology reports meaningful to patients: A plain language intervention"

- R. Davilene Carter Presidential Prize for Best Manuscript:

- First place: Aleksandra Ogrodnik, Ted James, Susan MacLennan, Donald Weaver: "Barriers to Completing Delayed Breast Reconstruction following Mastectomy"

- Second place: Katie Cueva, Laura Revels, Regina Kuhnley, Melany Cueva, Ann Lanier, Mark Dignan: "Co-Creating a Culturally-Responsive Distance Education Cancer Course with, and for, Alaska's Community Health Workers: Motivations from a Survey of Key Stakeholders"

- Third place: Darryl Schuitevoerder, Jeanine Fortino, John Vetto: "Hard Copy Durable Patient Cancer Education Materials: Do They Still Matter?"

- Selma Morris Memorial Travel Scholarship:

- Pedram Daraei

- Jill B. Hamilton 
2015 Journal of Cancer Education reviewers

Last name

Agunwamba

Akinyemiju

Almutairi

Alshahrani

Amato

Anderson

Anggondowati

Arnold

Baccaglini

Barton

Benard

Birken

Bishop

Blazer

Burhansstipanov

Burton-Chase

Cameron

Cercato

Chamberlain

Chang

Corley

Cueva

Curado

Dark

de Walden-Gałuszko

Dey

Dignan

Donelle

Drake

Dumitrescu

Elliott

Enard

Erwin

Ettinger

Faupel-Badger

Ferrell

Ferris

Ford

Friedman

Gaafar

Giardini

Golden

Goodall

Grant

Gronemeyer

Gwede

Gwede

Hablas
First name

Amenah

Tomi

Mesnad

Saad

Katharine

Kathryn

Trisari

Connie

Lorena

Michael

Vicki

Sarah

Maria

Kathleen

Linda

Allison

Carrie

Maria Cecilia

Robert

Shine

Brittany

Melany

Maria-Paula

Graham

Krystyna

Suhojit

Mark

Lorie

Bettina

Alexandrina

Thomas

Kimberly

Deborah

Susan

Jessica

Betty

Frank

Sabrina

Daniela

Rabab

Anna

Daniel

Mark

Marcia

Suzanne

Clement

Clement

Mohamed
Hansen

Hardy

Heron

Hoffman

Hoffman-Goetz

Howard-Hunt

Hughes

Islam

Jandorf

Jansen

Jimbo

John

johnstone

Kagawa Singer

Kamel

Katapodi

Katz

Kaur

Kepka

Khaled

Krebs

Laiyemo

Latini

Lester

Long

Luque

Mahoney

Mainvil

Margalit

Marshall

McCarthy

McDonald

McLaughlin

McWhirter

Meade

Merajver

Messner

Michalek

Micke

Milbury

Moore

Morgan

Mullan

Mutanga

Mutanga

Nasser

Nasser

Nelson-Marten

Ness

Nguyen

Nyhof Young

O’Donnell
Andrew

Elaine

Jean-François

Mark

Laurie

Barbara

Anne

KM

Lina

Liesbeth

Masahito

Sunitha

candice

Marjorie

Laila

Maria

Mira

Harpriya

Deanna

Hussein

Linda

Adeyinka

David

Joanne

Sarah

John

Martin

Louise

Ruth

Keri

Philip

Fiona

Robert

Jennifer

Cathy

Sofia

Carolyn

Arthur

Oliver

Kathrin

Charles

Robert

Patricia

Jane

Jane

Shafika

Shafika

Paula

Sheryl

Kim

Joyce

Joseph 


\begin{tabular}{|c|c|c|c|}
\hline Pal & Tuya & Soliman & Ghada \\
\hline Parpinel & Maria & Starmer & Darren \\
\hline Patel & Ketki & Stewart & Alex \\
\hline Patel & Asmita & Stoll & Christoph \\
\hline Perkins & Rebecca & Sue & Heiney \\
\hline Perocchia & Rosemarie & Sun & Virginia \\
\hline Quinn & Gwendolyn & Szumacher & Ewa \\
\hline Quintana & Yuri & Szumacher & Ewa \\
\hline Rankin & Kathleen Vendrell & Tarasenko & Yelena \\
\hline Rieke & Katherine & Tarkowski & Radoslaw \\
\hline Robinson & June & Tevaarwerk & Amye \\
\hline Rodriguez & Elisa & Thomas & Tami \\
\hline Roodenburg & Jan & Torres & Essie \\
\hline Ross & Douglas & Uijtdehaage & Sebastian \\
\hline Ross & Levi & Vercelli & Marina \\
\hline Ryan & Sheila & Vetto & John \\
\hline Sadler & Georgia & Villela-Castro & diana \\
\hline Scheurer & Michael & Vinson & Eric \\
\hline Schmid & Kendra & Vogtmann & Emily \\
\hline Seifeldin & Ibrahim & Weatherspoon & Darien \\
\hline Shafer & Kate & Wen & Kuang-Yi \\
\hline Shash & Emad & Wewers & Mary Ellen \\
\hline Shelton & Rachel & Wicher & Camille \\
\hline Sheppard & Vanessa & Wigfall & Lisa \\
\hline Shockney & Lillie & Wiljer & David \\
\hline Siahpush & Mohammad & Williams & Karen Patricia \\
\hline Silver & Julie & $\mathrm{Xu}$ & Lei \\
\hline Simon & Melissa & Yates & Jerome \\
\hline Smallwood & Stacy & Yoo & Grace \\
\hline Smith & Brittney & Zheng & $\mathrm{Yu}$ \\
\hline
\end{tabular}

